\title{
Comparison of Globally Recognized ICT and Telecommunications Indices
}

\author{
Thipchutar Paparwekorn
}

\begin{abstract}
Nowadays, many globally recognized organizations and institutes have introduced a number of indices related to telecommunications sector. Each index has gained significant attention from the public and private sectors around the world because the results of such national ranking under these indices have a direct impact on reliability, national competitiveness and investment attractiveness. They are then thoroughly analyzed by policy makers and private organizations alike to identify the areas for improvement aiming to achieve better ranking in the upcoming rounds. However the high number of such indices may create confusion among investors and analysts and raise concerns among policy makers, especially regarding the way each index is calculated or ranked. Those indices, relevant to telecommunications industry at present, are formulated to measure the level of development in the telecommunications and ICT and consequently create visible impacts on the country's economic growth. Therefore the preparation of these indices should aim to focus at the factors to stimulate growth, to drive the industry further, and to identify sustainability. This paper compares the different ICT and telecommunications indices developed by various organizations across the globe to highlight the factors impacting economic growth. Recommendations for supportive policies and strategies are provided in this paper on how to improve ICT indices ranking to foster socio-economic benefits for countries.
\end{abstract}

Index Terms-Comparison, ICT, telecommunications, index.

\section{INTRODUCTION}

Historically, the degree of global business integration has been shaped by communication over long-distances but today it is influenced rather by the emergence of new technologies that reduce the costs of conducting business and communication over increased geographical distances. However, the impact of ICT has changed throughout the years, from just allowing cost effective communication through extended geographical distances to permitting online commerce, online banking, online media, e-learning and many more. Therefore, ICT, particularly the internet, is having a significant impact on the operations of business enterprises and is claimed to be essential for the survival and growth of nations' economies. So, the magnitude of information and communications technologies (ICTs) as a powerful tool for socio-economic development is now widely acknowledged not only among developed countries but by developing countries as well. Though the use of ICT to enhance business growth in every country is top on governments' development agenda, skills shortage remains

Manuscript received July 17, 2015; revised November 5, 2015.

Thipchutar Paparwekorn is with the Office of National Broadcasting and Telecommunications Commission (NBTC), Thailand (e-mail: gameooboyxx@hotmail.com). the greatest obstacle. Therefore, there is a need more now than ever to evaluate the current ICT index of each country, identify gaps for improvement and then create a long-term plan to increase the ICT index of each country. Nevertheless, as there are various ICT and telecommunications indices developed by various organizations across the globe, this research aims to analyze each ICT index in order to highlight the factors impacting economic growth.

\section{A. Why Indices Are Important?}

An index is comprised of multiple relevant indicators/variables that can be concluded into a single value to evaluate effectiveness on a certain subject. For instance, the value for ICT index is scored from multiple relevant indicators into a single value and can represent the ICT development score and ranking of a country. The main advantage of having an index is that ICT development can be benchmarked against other countries, categories or regions. Comparison against other countries that have similar income level, geographical characteristics, and social or regional characteristics is extremely valuable, as it can be used to create realistic targets and policy decisions can be concluded to measure ICT development over time [1].

Time series index on ICT index of every country, allows for detailed comparison and permits policy makers to judge the effectiveness of the country's ICT development programs and initiative. Countries often struggle in some areas of ICT development, and ICT index can be a trigger to identify in which area they have a weakness in, so that a country's government can focus on those areas and excel over other countries and improve its ICT development ranking from last year. Although just a score, ICT index captures multiple effects and tells a wider story of what needs to be done. Factors such as changes in demographics, socio-economic development and income level can also have a major impact and is reflected in the index.

Although the benefits of index ranking are substantial in providing direction for the country in policy and development, there are limitations when it is concluded into a single figure. We must bear in mind that it is useful in benchmarking and comparison but could give biased results if simplistic conclusions are drawn from the index. All single value scoring and rankings of this nature have high limitations because of the methodological assumptions that may not be valid for every country, and also in cases where there is incorrect or missing data for some of the multiple indicators.

These limitations can be mitigated if the indices limit number of economies, have greater detail and feature large number of variables - resulting in a smaller set of "well-covered" economies. Covering all economies requires limiting the number of variables/multiple criterion used. 
Covering a wide range of economies on the other hand, requires limiting the number of variables used.

\section{RESEARCH METHODOLOGY}

The aim of this research is to evaluate widely used ICT indices and provide recommendations on how to improve ICT indices ranking, so countries can drive socio-economic benefits by prioritizing the most pertinent ICT development factors. To achieve this goal, the paper adopts the in-depth interview approach to explore the research objective. In this research, the secondary source information is from academic papers, business reports and industrial analysis reports. We classified subject matter experts into five categories depending on their area of expertise in ICT technologies, Economics, Social science, Policy and strategic management. The total number of subject matter experts or respondents is 15 with 3 from each key focus area as shown in Table I.

\begin{tabular}{lc} 
TABLE I: INTERVIEWING EXPERTS AND KEY FOCUS \\
\hline \multicolumn{1}{c}{ Area of expertise } & Numbers \\
\hline ICT Technology & 3 \\
\hline Economic & 3 \\
\hline Social Science & 3 \\
\hline Law & 3 \\
\hline Strategic management & 3 \\
\hline \hline
\end{tabular}

\section{COMPARISON OF GLOBALLY RECOGNIZED TELECOMMUNICATIONS INDICES}

\section{A. The Networked Readiness Index (NRI) by The World Economic Forum (WEF)}

Networked Readiness Index (NRI) is designed to measure the ICT readiness, usage and impact in a country [1]. This index is released every year by The World Economic Forum (WEF). NRI covers various aspects of telecommunications and ICT with 54 factors, arranged into 4 sub-indices and 10 pillars as follows.

1) Environment sub-index

Pillar 1: Political and regulatory environment

Pillar 2: Business and innovation environment

2) Readiness sub-index

Pillar 3: Infrastructure and digital content

Pillar 4: Affordability

Pillar 5: Skills

3) Usage sub-index

Pillar 6: Individual usage

Pillar 7: Business usage

Pillar 8: Government usage

4) Impact sub-index

Pillar 9: Economic impacts

Pillar 10: Social impacts

WEF together with INSEAD, the leading business institute in France, publishes its study through the Global Information Technology Report (GITR) annually. NRI measures the readiness, environments, usage, and impacts of ICT and is the only index which has been published annually since 2002 .

In 2014, Thailand ranked 67 (out of 148 countries) with 4.01 points, which is better than the ranking in 2013 (74 from 144 countries). Thailand has continuously improved its ranking since 2012. However, among AEC members, Thailand was overtaken by Indonesia and ranked 5, dropped from the ranking in 2013 at number 4,. The NRI score and ranking of AEC members are presented in the table below.

TABLE II: ICT READINESS RANKING AMONG ASEAN COUNTRIES USING NETWORK READINESS INDEX (NRI) [2]

\begin{tabular}{|c|c|c|c|c|c|c|}
\hline Country & $\begin{array}{l}\text { NRI value } \\
(2014)\end{array}$ & $\begin{array}{l}\text { AEC rank (global rank out of } \\
148) 2014\end{array}$ & $\begin{array}{l}\text { NRI value } \\
(2013)\end{array}$ & $\begin{array}{l}\text { AEC rank (global rank } \\
\text { out of 144) } 2013 \\
\end{array}$ & $\begin{array}{l}\text { NRI value } \\
(2012)\end{array}$ & $\begin{array}{c}\text { AEC rank (global rank } \\
\text { out of 142) } 2012 \\
\end{array}$ \\
\hline Singapore & 5.97 & $1(2)$ & 5.96 & $1(2)$ & 5.86 & $1(2)$ \\
\hline Malaysia & 4.83 & $2(30)$ & 4.82 & $2(30)$ & 4.8 & $2(29)$ \\
\hline Brunei & 4.34 & $3(45)$ & 4.11 & $3(57)$ & 4.04 & $3(54)$ \\
\hline Indonesia & 4.04 & $4(64)$ & 3.84 & $5(76)$ & 3.75 & $5(80)$ \\
\hline Thailand & 4.01 & $5(67)$ & 3.86 & $4(74)$ & 3.78 & $4(77)$ \\
\hline Philippines & 3.89 & $6(78)$ & 3.73 & $7(86)$ & 3.64 & $7(86)$ \\
\hline Cambodia & 3.36 & $8(108)$ & 3.34 & $8(106)$ & 3.32 & $8(108)$ \\
\hline Lao PDR & 3.34 & $9(109)$ & $\mathrm{n} / \mathrm{a}$ & $\mathrm{n} / \mathrm{a}$ & $\mathrm{n} / \mathrm{a}$ & $\mathrm{n} / \mathrm{a}$ \\
\hline Myanmar & 2.35 & $10(146)$ & $\mathrm{n} / \mathrm{a}$ & $\mathrm{n} / \mathrm{a}$ & $\mathrm{n} / \mathrm{a}$ & $\mathrm{n} / \mathrm{a}$ \\
\hline
\end{tabular}

\section{B. The Digital Economy Rankings (DER) Prepared by the Economist Intelligent Unit (EIU)}

Economist Intelligence Unit (EIU) is a unit in The Economist magazine that invented and developed a method to generate the Digital Economy Rankings together with IBM Institute for Business Value. The name and calculation method was changed from the original e-readiness rankings to reflect the higher influence of ICT over society and economy. This ranking covered 70 countries around the world.

It consists of 39 factors, grouped into 6 following types with different weightings to calculate the overall ranking.

1) Connectivity and technology infrastructure with $20 \%$ weight
2) Business environment with $15 \%$ weight

3) Social and cultural environment with $15 \%$ weight

4) Legal environment with $10 \%$ weight

5) Government policy and vision with $15 \%$ weight

6) Consumer and business adoption with $25 \%$ weight

The ranking results among AEC members are shown in Table III below.

Even though the Digital Economy Rankings covers many aspects of ICT readiness just like NRI, it was prepared only once in 2010. Therefore its validity and relevance reduces over time.

C. The ICT Development Index (IDI) by International

Telecommunication Union (ITU)

ICT Development Index (IDI) by the International 
Telecommunications Union (ITU) is the ranking to measure a country's ICT development status [4]. This is an important tool for governments, service providers, researchers, developers and many other organizations to compare a country's ICT performance and to measure digital divide. IDI consists of 11 indicators that fall into 3 categories with different weights as given below.

1) ICT access with $40 \%$ weight including 5 indicators
2) ICT use with $40 \%$ weight including 3 indicators

3) ICT skills with $20 \%$ weight including 3 indicators

Comparing with NRI and DER, IDI focuses more on ICT use and ICT access. It does not take into account the other economic or social factors influencing ICT or being affected by ICT. ITU calculates IDI and publishes it in the Measuring the Information Society every year. The table below shows the results of IDI on Asia and the Pacific in recent years.

TABLE III: DigitAL ECONOMY RANKINGS AMONG ASEAN MEMBERS USING DER [3]

\begin{tabular}{l|l|l|l|l|l|l|l|l}
\hline \hline Country & $\begin{array}{c}\text { AEC** } \\
\text { rank }\end{array}$ & $\begin{array}{c}\text { DER } \\
\text { value }\end{array}$ & $\begin{array}{c}\text { Connectivity and } \\
\text { technology } \\
\text { infrastructure } \\
(20 \%)^{*}\end{array}$ & $\begin{array}{c}\text { Business } \\
\text { environment } \\
(15 \%)^{*}\end{array}$ & $\begin{array}{c}\text { Social and cultural } \\
\text { environment } \\
(15 \%)^{*}\end{array}$ & $\begin{array}{l}\text { Legal environment } \\
(10 \%)^{*}\end{array}$ & $\begin{array}{l}\text { Government policy } \\
\text { and vision }(15 \%)^{*}\end{array}$ & $\begin{array}{l}\text { Consumer and } \\
\text { business } \\
\text { adoption } \\
(25 \%)^{*}\end{array}$ \\
\hline Singapore & $1(8)$ & 8.22 & $7.35(1)$ & $8.63(1)$ & $7.33(1)$ & $8.70(1)$ & $9.13(1)$ & $8.48(1)$ \\
\hline Malaysia & $2(38)$ & 5.93 & $4.35(2)$ & $7.36(2)$ & $5.47(2)$ & $6.88(2)$ & $6.65(2)$ & $5.80(2)$ \\
\hline Thailand & $3(49)$ & 4.86 & $3.20(3)$ & $6.83(3)$ & $4.50(3)$ & $6.35(3)$ & $5.60(3)$ & $4.18(4)$ \\
\hline Philippines & $4(54)$ & 4.47 & $2.60(5)$ & $6.35(4)$ & $4.27(4)$ & $4.85(4)$ & $5.20(4)$ & $4.38(3)$ \\
\hline Vietnam & $5(64)$ & 3.87 & $3.20(3)$ & $5.70(6)$ & $3.60(5)$ & $4.65(5)$ & $4.60(5)$ & $2.71(5)$ \\
\hline Indonesia & $6(65)$ & 3.6 & $2.60(5)$ & $6.04(5)$ & $3.60(5)$ & $4.20(6)$ & $3.88(6)$ & $2.55(6)$ \\
\hline \hline
\end{tabular}

Note: ** Global ranking in shown in brackets (from 70 countries) * AEC ranking in brackets

TABLE IV: RANKING OF ICT DEVELOPMENT FOR ASIA AND THE PACIFIC USING IDI METHODOLOGY [4]

\begin{tabular}{|c|c|c|c|c|c|c|}
\hline Country & $\begin{array}{c}\text { Regional rank } \\
2013\end{array}$ & $\begin{array}{c}\text { Global rank } \\
2013\end{array}$ & $\begin{array}{c}\text { IDI } \\
2013\end{array}$ & $\begin{array}{c}\text { Global rank } \\
2012\end{array}$ & IDI 2012 & $\begin{array}{c}\text { Global rank } \\
\text { change } \\
2012-2013\end{array}$ \\
\hline Korea (Rep.) & 1 & 2 & 8.85 & 1 & 8.81 & -1 \\
\hline Hong Kong, China & 2 & 9 & 8.28 & 11 & 8.08 & 2 \\
\hline Japan & 3 & 11 & 8.22 & 10 & 8.15 & -1 \\
\hline Australia & 4 & 12 & 8.18 & 12 & 8.03 & 0 \\
\hline Singapore & 5 & 16 & 7.90 & 15 & 7.85 & -1 \\
\hline New Zealand & 6 & 19 & 7.82 & 19 & 7.62 & 0 \\
\hline Macao, China & 7 & 22 & 7.66 & 20 & 7.59 & -2 \\
\hline Brunei Darussalam & 8 & 66 & 5.43 & 63 & 5.36 & -3 \\
\hline Malaysia & 9 & 71 & 5.20 & 66 & 5.18 & -5 \\
\hline Thailand & 10 & 81 & 4.76 & 91 & 4.09 & 10 \\
\hline Maldives & 11 & 85 & 4.71 & 82 & 4.50 & -3 \\
\hline China & 12 & 86 & 4.64 & 86 & 4.39 & 0 \\
\hline Fiji & 13 & 91 & 4.40 & 103 & 3.90 & 12 \\
\hline Mongolia & 14 & 92 & 4.32 & 90 & 4.19 & -2 \\
\hline Iran (I.R.) & 15 & 94 & 4.29 & 97 & 4.02 & 3 \\
\hline Viet Nam & 16 & 101 & 4.09 & 99 & 3.94 & -2 \\
\hline Philippines & 17 & 103 & 4.02 & 102 & 3.91 & -1 \\
\hline Indonesia & 18 & 106 & 3.83 & 106 & 3.70 & 0 \\
\hline Sri Lanka & 19 & 116 & 3.36 & 113 & 3.31 & -3 \\
\hline Bhutan & 20 & 123 & 2.85 & 126 & 2.58 & 3 \\
\hline Cambodia & 21 & 127 & 2.61 & 127 & 2.54 & 0 \\
\hline India & 22 & 129 & 2.53 & 129 & 2.42 & 0 \\
\hline Nepal & 23 & 131 & 2.37 & 134 & 2.20 & 3 \\
\hline Lao P.D.R. & 24 & 134 & 2.35 & 130 & 2.25 & -4 \\
\hline Solomon Islands & 25 & 136 & 2.29 & 132 & 2.22 & -4 \\
\hline Pakistan & 26 & 142 & 2.05 & 141 & 2.01 & -1 \\
\hline Bangladesh & 27 & 145 & 1.97 & 146 & 1.90 & 1 \\
\hline Myanmar & 28 & 150 & 1.82 & 148 & 1.75 & -2 \\
\hline Afghanistan & 29 & 155 & 1.67 & 155 & 1.57 & 0 \\
\hline Average & & & & & & \\
\hline
\end{tabular}

\section{The Telecommunications Regulatory Governance} Index (TRGI) Prepared by Waverman L., and Koutroumpis

TRGI is the indicator used to measure performance of telecommunication regulators around the world [5]. It is prepared by Canadian researchers from University of Calgary in Canada in collaboration with Imperial College London in England and European Investment Bank. TRGI accesses operating performance of telecommunications regulators in 4 aspects:
1) Transparency

2) Independence

3) Resource availability

4) Enforcement

TRGI uses 18 indicators which are grouped into 4 categories mentioned above with equal weight. The results from this research are used to rank the readiness of telecommunications commissions around the world including other sub-indexes. TRGI was published in the academic paper 
related to telecommunications policy in September 2011 [5].

\section{COMPARISON OF IMPORTANT TELECOMMUNICATIONS INFORMATION}

There are many organizations and institutes that published information or statistics about telecommunications industry. The widely recognized ones are from and World Bank.

\section{A. World Telecommunication/ICT Indicators Database prepared by International Telecommunication Union (ITU)}

The International Telecommunication Union (ITU) has been publishing the World Telecommunication/ICT Indicators Database in time series collected in 1960, 1965, 1970 and annually since 1975 . There are more than 150 important statistical values related to telecommunications and ICT including information about fixed-line network, mobile network, number of subscribers, service quality, internet service, price, income, investment, and the information about ICT access and ICT usage in household and individual level.

Data come from more than 200 countries answering the queries sent from ITU to the relevant parties in each country, mostly the telecommunication/ICT regulators or ministries. ITU also gathers information from additional reports sent by the relevant ministries or regulators as well as other ITU internal reports. In some cases, there are estimations in the calculation, based on certain assumptions made by ITU officials. In such cases, the relevant information is clearly written.

This database from ITU is highly valuable to measure and compare the readiness and performance of ICT industry of each country. This information is also used to calculate some indices described earlier, such as IDI.

\section{B. The Little Data Book on Information and}

Communication Technology Prepared by the World Bank and ITU

World Bank has prepared The Little Data Book on Information and Communication Technology in association with ITU, which has the information about telecommunication industry in 2005 and 2012 collected from countries and regions around the world. This report has information related to different aspects as followed:

1) Economic and social context

2) ICT sector structure

3) ICT sector efficiency and capacity

4) ICT sector performance

- Access

- Usage

- Quality

- Affordability

- Trade

- Applications

Just like the ICT information from ITU, the ICT information published by World Bank though this report has been used to compare the ICT performance between different countries or used to calculate indices. One interesting point is that the information World Bank has chosen to show in this report already reflects as indicators to compare the ICT development.

\section{RECOMMENDATIONS TO IMPROVE THE ICT INDICES AND SOCIO-ECONOMIC BENEFITS}

Recommendations to Improve the ICT indices and socio-economic benefits analysis in this paper concluded the recommendations to drive possible maximum socio-economic benefits as follows:

1) To ensure national broadband plan provides measureable and actionable goals that are more than just general set of aspirations. The government needs to create realistic goals on changing structure and processes that enables broadband penetration and ICT development. Government must set a coordination party works aggressively towards ensuring cooperation and integration of broadband plan between high-level ministries, regulator and private operators, and working towards the same goals. As working towards the same goals and direction is the key to achieving a national broadband plan. Ideally government must ensure that the coordinating party works towards meeting all goals and KPIs and it must be achieved in within a given timeframe. The coordinating party assigned by government should be empowered to work with all national and local governments to implement policies, address legislation, specific obstacles and eliminate hindrance to achieving national broadband plan goals.

2) At times there is a major difference between assigning spectrum to highest bidder and assigning spectrum to highest value adding service. Governments must set rules and regulations for spectrum assignment that are fair, transparent, deters spectrum hoarding and anti-competitive behavior and at the same time, earn revenue for national treasury that reflects the value of that spectrum band. Most importantly, the license conditions for spectrum must be designed in a way that it encourages rapid deployment of mobile broadband infrastructure and must ensure technology neutrality so it does not hamper adoption of new technologies.

3) To minimize uncertainty in spectrum licensing, regulators and governments must work together to ensure nothing can impact continuity of service. The regulator needs to eliminate political instability and ensure spectrum license renewal approach is transparent, predictable and coherent. All stakeholders that are impacted must be involved at all stages of decision making on these aspects. Most importantly, the regulator and government must work towards eliminating red tape or unnecessary and time consuming spectrum licensing process to ensure that spectrum is assigned at a faster rate to catch up with the rapidly growing customer demand for mobile broadband.

4) In most countries, the amount of radio spectrum that is currently allocated and in use by the mobile industry is between $500 \mathrm{MHz}$ and $5 \mathrm{GHz}$. To ensure economies of scale, remove of interference issues between neighboring countries and elimination of technical issues, harmonization is of utmost importance. The regulator must ensure spectrum band plan that is recommended by ITU-R taking into consideration and strictly followed to the best of its ability. Government must ensure regulator 
has its full support in attempts to voluntarily free up currently occupied spectrum bands for mobile broadband. This is to ensure widespread deployment of broadband to cater to growing demand and ensuring equal access to broadband for all national citizens.

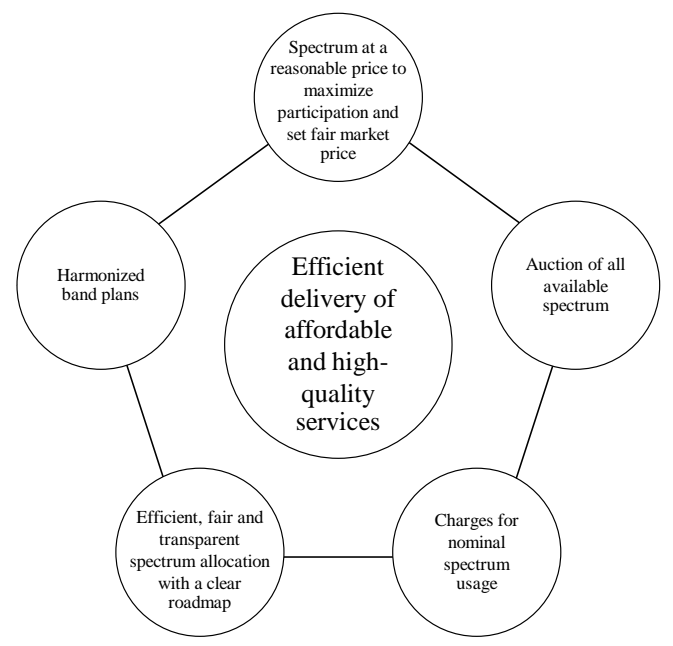

Fig. 1. Spectrum-related factors crucial for service delivery.

5) A national broadband plan should ensure that existing universal service funds are targeted, time-bound and managed transparently. The funds should be allocated via a competitive approach and cost of deploying such service is in line with the consultation given by the industry. Therefore, the winning bidder is the one with the most cost effective approach to universal service deployment. Moreover, governments should consider incentives that facilitate market-based solutions - the vast majority of coverage expansion is driven by private investment, following the provision of new spectrum and the availability of more efficient technologies.

6) The national broadband plan must facilitate infrastructure sharing to ensure a society benefit on widespread coverage is reached. Governments and national regulators should write up legislation to support voluntary sharing of infrastructure and even educate and encourage private sector on this matter. Ideally, a country's regulatory framework should facilitate all types of infrastructure sharing arrangements, involving the sharing of both passive and active components of mobile networks.

7) A national broadband plan needs to set an encouraging environment fit for advent in technologies, and must ensure policy and regulation implemented does not deter technological advancement and innovation. At the same time, as telecom industry is prone to have large competitors and competition concentrated amidst a very few competitors, regulators must implement policies to alleviate excessive competition and monopolistic behavior to ensure investments in the sector are not deterred. The key is to ensure that the sector is not over regulated such that it impedes technology innovation and not under regulator such that excessive competition deters investment.

8) Spectrum is a scarce valuable resource that is an essential foundation of ICT development and national competitiveness. It is not only essential for telecommunication services but is also critical for use during national disasters and military critical missions. The lack of spectrum planning and roadmap for future use can affect telecom industry and many other sectors adversely, hence ultimately result in national competitive disadvantage. Several spectrum-related issues such spectrum-related policies especially those relating to optimum pricing are critical for growth of telecom services. Fig. 1 shows spectrum related factors crucial service delivery [6].

\section{CONCLUSION}

After the comparison between different telecom indices and information from different respectable sources, there are certain commonly used factors which can be grouped into 5 categories-infrastructure and accessibility, national regulatory agency (NRA) and ICT policy, business environment, education and innovation, and usage and security.

The contribution of this research is to highlight the strengths and weaknesses of each index, As there are high number of indices which may create confusion among investors, analysts and policymakers regarding the way the index is calculated or ranked. Thorough analysis has shown in the above research that in some cases, some assumptions from certain indices may not be applicable for certain countries, resulting in unrealistic ranking. As a result, it is recommended that each country evaluates ranking from all indices also checking their methodology to evaluate whether the data used to conclude the ranking is recent and fitting.Finally, the paper provided recommendations on how to improve ICT indices ranking, so countries can drive socio-economic benefits by prioritizing the most pertinent ICT development factors.

\section{REFERENCES}

[1] United Nations, Information and Communication Technology (ICT) Development Indices, World Summit on Information Society: UNCTAD/ITE/TEB/MISC.2, vol. III. 2003.

[2] We Forum and INSEAD, "The global information technology report 2014," 2014.

[3] Economist Intelligence Unit and IBM, "Digital economy rankings 2010 beyond e-readiness," 2010.

[4] ITU, "Measuring the information society report," 2014.

[5] L. Waverman and P. Koutroumpis, "Benchmarking telecoms regulation - The telecommunications regulatory governance index (TRGI)," Telecommunications Policy, vol. 35, pp. 450-468, 2011.

[6] Vodafone, "Spectrum policy in emerging markets," The Policy Paper Series, no. 15, 2014.

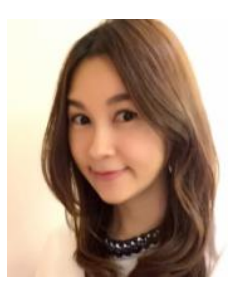

Thipchutar Paparwekorn received her bachelor of liberal arts from Sripatum University, Thailand, 2003, and the MBA from Assumption University, Thailand, 2013. Her current research interests are in strategic management, brand management and marketing management. She is currently working as an advisor to the Chairman of a global company based in Thailand. She worked on several research projects in diverse fields such as managing all communication channels in both mass media and internal media. 